\title{
Entre a cidade legal e a cidade ilegal: a realidade das pequenas cidades da Amazônia - um estudo de Ponta de Pedras, Pará
}

\author{
Between the legal and illegal city: the reality of small towns in the \\ Amazon Region - a case study of Ponta de Pedras, Para
}

Sandra Maria Fonseca da Costa ${ }^{[0]}$, Jéssica Andretta Mendes ${ }^{[b]}$, Viviana Mendes Lima ${ }^{[c]}$, Bruno Henrique Colombari Moreira ${ }^{[d]}$

[a] Geógrafa, doutora em Informação Espacial pela Universidade de São Paulo (USP), professora adjunta da Universidade do Vale do Paraíba (UNIVAP), São José dos Campos - Brasil, e-mail: sandra@univap.br

[b] Geógrafa e bolsista técnica do Laboratório de Estudo das Cidades da Universidade do Vale do Paraíba (UNIVAP), São José dos Campos - Brasil

[c] Geógrafa, mestre em Planejamento Urbano e Regional pela Universidade do Vale do Paraíba (UNIVAP), São José dos Campos - Brasil

[d] Bolsista de Iniciação Científica do CNPq, estudante de Geografia da Universidade do Vale do Paraíba (UNIVAP), São José dos Campos - Brasil

\section{Resumo}

A ilegalidade em relação à propriedade da terra tem sido um dos principais elementos da segregação socioespacial, no campo ou na cidade. A informalidade urbana no Brasil tem raízes históricas, principalmente associadas ao acesso a terra. De acordo com informações disponíveis, cerca de $20 \%$ dos municípios da Amazônia Legal possuíam legislação sobre regularização fundiária e cerca de 14\% possuem plano ou programa específico de regularização fundiária. A cidade de Ponta de Pedras, localizada na ilha de Marajó, estado do Pará, é um exemplo dessa situação — também verificada em outras pequenas cidades do estuário do rio Amazonas. Na cidade, foram registrados no cartório local 621 imóveis urbanos, de 1899 a 2011, e a Prefeitura tem cadastrados, para efeito de cobrança do IPTU, 1.888 imóveis urbanos. Uma discussão que precisa avançar, em relação à regularização fundiária nas cidades da Região Amazônica, refere-se a essa noção de urbano e à percepção da população e do poder público local sobre as formas de apropriação desse espaço. Essa discussão é importante para subsidiar a elaboração de políticas regionais que viabilizem o desenvolvimento regional com qualidade de vida.

Palavras-chave: Cidade ilegal. Propriedade da terra. Pequenas cidades. Região Amazônica.

\section{Abstract}

Illegality concerning land ownership has been one component of socio-spatial segregation in rural or urban areas. The urban informality has historical explanations in Brazil, mainly associated with land access. 
In the Brazilian Amazon, around 20\% of the municipalities had laws on land regularization and about $14 \%$ have a plan or program of land regularization. The city of Ponta de Pedras, located on the island of Marajo, state of Para, is an example of this situation, which is also observed in other small towns in the Amazon River estuary. In the local registry office, 621 urban properties were registered from 1899 to 2011, and Department of Municipal Finance has registered 1.888 properties for collecting taxes. A discussion that needs to move forward in relation to land tenure in the cities of the Amazon Region refers to the notion of urban and what perception the population and local government have about the appropriation of this space. This is an important discussion to subsidize the development of regional policies that enable regional development with quality of life.

Keywords: Illegal city. Legal city. Land tenure. Small towns. Amazon Region.

\section{Introdução}

A Região da Amazônia Legal tem sido considerada urbana desde 1980, quando a população urbana da região ultrapassou os residentes em áreas consideradas rurais (COSTA et al., 2009). Além de ter vivenciado diferentes períodos econômicos, tais como a exploração da borracha, o comércio de produtos florestais, a extração do palmito e a produção da mandioca, a Região também foi alvo de políticas públicas federais de incentivo à ocupação do território após a década de 1960, o que causou uma intensa migração para a Amazônia e suas cidades.

De acordo com o Censo de 2010 (INSTITUTO BRASILEIRO DE GEOGRAFIA E ESTATÍSTICA, 2012), mais de $80 \%$ da população da Amazônia Legal vive em cidades, de diferentes dimensões. Em 2000, 27\% da população urbana vivia em 639 cidades (com menos de 20 mil habitantes), as quais representavam, aproximadamente, $84 \%$ do total de 760 cidades sedes dos municípios localizados na Amazônia Legal (COSTA et al., 2009). Em 2010, essa porcentagem diminuiu para $82 \%$; entretanto, as pequenas cidades continuam predominando.

De acordo com Costa e Brondizio (2011, p. 212), essas pequenas cidades, apesar de possuírem economia frágil, forte dependência do repasse dos subsídios do governo federal e baixa competência em oferecer serviços e equipamentos urbanos, tais como educação, saúde e infraestrutura, cumprem um papel importante na rede urbana da Amazônia. Para os autores, essas cidades funcionam como salvaguarda para as famílias rurais acessarem os serviços urbanos e oportunidades de emprego, que são precárias ou inexistentes nas áreas rurais.
Esse crescimento urbano, apesar de suas peculiaridades, reproduz um padrão urbano muito usual às cidades brasileiras, sendo o mais particular a reprodução da irregularidade fundiária no processo de ocupação. A professora Ermínia Maricato (MARICATO, 2002) explica que, no Brasil, foram construídas, entre 1995 e 1999, cerca de 4,4 milhões de moradias, sendo que apenas 700 mil foram produzidas pelo mercado formal. Sendo assim, mais de três milhões de moradias, naquele período, foram construídas em terras invadidas ou em áreas inadequadas. Ressalta-se que a ineficiência de políticas públicas, ou mesmo a sua ausência, favorecem a reprodução dessa situação, ainda atualmente.

A ilegalidade em relação à propriedade da terra tem sido um dos principais elementos da segregação socioespacial, no campo ou na cidade. Para Maricato (2003, p. 155), essa ilegalidade "parece fornecer, frequentemente, uma base para que a exclusão se realize em sua globalidade".

No processo de crescimento urbano, a lógica do mercado imobiliário propicia a divisão da cidade em cidade legal e cidade ilegal (MARICATO, 2002; ROLNIK, 2006). A cidade legal é a aquela parte da cidade que é contemplada pelo poder público que busca suprir as necessidades de infraestrutura, além de ser valorizada pelo mercado imobiliário. Ao mesmo tempo, a "cidade ilegal" se refere à porção irregular da cidade, não reconhecida pelo poder público em termos de planos urbanísticos, sendo caracterizada por Maricato (2002) como o "lugar fora das ideias".

Gouvêa, Ávila e Ribeiro (2009, p. 86) afirmam que, na Amazônia Legal, em torno de $20 \%$ dos municípios possuíam legislação sobre regularização fundiária e cerca de $14 \%$ possuem plano ou programa 
específico de regularização fundiária. De acordo com os autores, esses valores não são expressivos, entretanto estão acima da média nacional - 15\% e 11\%, respectivamente. A existência desses planos não é garantia de que o processo de regularização fundiária está em curso ou já tenha ocorrido, mas é um indicador que deve ser considerado.

A cidade de Ponta de Pedras, localizada na ilha de Marajó, estado do Pará, é um exemplo dessa situação, também verificada em outras pequenas cidades do estuário do rio Amazonas. Apesar da precariedade de serviços e de habitabilidade urbanos, a cidade de Ponta de Pedras atrai população do entorno imediato, pois é possível ter acesso à água encanada, à rede elétrica, à educação, dentre outros equipamentos urbanos e, sobretudo, pela modernidade que tudo isso representa (MONTOIA, 2010). A discussão sobre a regularização fundiária urbana, como afirma Montoia (2010), aparece de forma discreta no Plano Diretor, aprovado em 2006, e os dados disponíveis sobre os mecanismos de registro de imóveis reforçam a necessidade de se discutir essa temática para se compreender a situação da legalidade da terra urbana.

Para contribuir com essa temática, esse artigo visa discutir a realidade da regularização fundiária urbana de uma pequena cidade da Amazônia, considerando os mecanismos de registro de imóveis e de transferência de propriedade na cidade de Ponta de Pedras. Por meio deles, será possível comparar dados multifontes, que podem auxiliar na compreensão da legalização da propriedade da terra urbana.

Este artigo descreve os métodos utilizados para obtenção e análise desses dados, de forma a compreender a regularização fundiária na cidade de Ponta de Pedras. A partir desse estudo, espera-se extrapolar os resultados para uma investigação mais ampla, abrangendo as pequenas cidades da Região Amazônica. Em uma região como a Amazônica, é interessante que se façam estudos sobre o processo de parcelamento da terra, pois, de acordo com Montoia (2010), existe um crescimento urbano disperso e as ocupações urbanas não são regularizadas - fatos que se refletem na qualidade de vida da população.

\section{Regularização fundiária urbana e acesso a terra}

A informalidade urbana no Brasil tem raízes históricas, principalmente associadas ao acesso a terra. Como mencionado por Schwarz e Arantes, "a exceção é a regra e a regra é exceção’ numa sociedade onde a maioria não alcança a condição de cidadania" (SCHWARZ; ARANTES apud MARICATO, 2003, p. 153).

No processo de urbanização brasileira, a apropriação do território brasileiro sempre esteve associado às possibilidades e vantagens ligadas ao acesso a terra. De acordo com Gouvêa, Ávila e Ribeiro (2009, p. 76), o sistema de ocupação, desde o início, no século XVI, ocorreu por meio da concessão de glebas aos homens de confiança da Coroa Portuguesa. "A prática da concessão de sesmaria institucionalizou o fenômeno dos latifúndios e, na ausência de sanções governamentais, surgem poderosas famílias interioranas que derivam o seu poder e influência baseadas no domínio sobre a propriedade das terras" (DELSON apud GOUVÊA; ÁVILA; RIBEIRO, 2009, p. 76).

Após o fim do sistema de sesmarias, no início do século XIX, o regime de posses se intensificou, até entrar em vigor a Lei n. 601, de setembro de 1850 Lei de Terras (GOUVÊA; ÁVILA; RIBEIRO, 2009).

\begin{abstract}
No período entre a Independência do Brasil e a Lei de Terras, o país deixa de contar com legislação de titulação de terra pública e a posse informal da terra continua existindo, sendo que as propriedades eram transmitidas por simples contrato, posse ou herança, bastando comprovar a posse para que a propriedade fosse transmitida, o que deu margem a extenso apossamento de terras. A ausência de registros formais também abria espaço ao surgimento de toda sorte de fraudes, causando insegurança nas relações comerciais que utilizavam os imóveis como garantia de crédito (GOUVÊA; ÁVILA; RIBEIRO, 2009, p. 77).
\end{abstract}

Para a professora Emília Viotti (apud COSTA, 1999) e o professor Manoel Correa de Andrade (ANDRADE, 1996), essa Lei estabeleceu que a aquisição de terras públicas só seria permitida por meio de compra, e incluiu critérios para a regularização das posses antigas. A Lei também proibia a posse e a doação de terras devolutas. É nesse momento que, como ressalta a professora Ermínia Maricato, a lei "distingue, pela primeira vez na história do país, o que é solo público e o que é solo privado" (MARICATO, 1997, p. 23).

Segundo Gouvêa, Ávila e Ribeiro (2009, p. 77), a Lei de Terras "consolida a propriedade privada, garantindo a exclusividade dos proprietários de terras 
existentes [...]. A alocação de terras exclusivamente pela compra favoreceu a elite econômica, resultando na concentração da terra e no acirramento das desigualdades sociais". Essa Lei fez com que houvesse uma mudança de parâmetro de poder e riqueza das elites daquele momento, que deixou de ser pelo número de escravos que possuíam e tornou-se a quantidade de terra sob seu domínio. Estabelece, também, um padrão de regulamentação de acesso à terra urbana, pois, ao definir o que eram as terras devolutas, define que aqueles que não fossem proprietários e ocupassem terras sem a aquisição formalizada pela compra não teriam a propriedade da terra.

\section{Algumas discussões sobre regularização fundiária}

De acordo com Vasconcelos (2011), nos países de economia periférica, os agentes não capitalistas tais como os proprietários fundiários e, principalmente, os invasores e ocupantes de terrenos - têm uma participação importante na estruturação das cidades, assim como o Estado.

O Estado desempenha múltiplos papéis em relação à produção do espaço. Essa multiplicidade decorre do fato de o Estado constituir uma arena em que diferentes conflitos se enfrentam (CORRÊA, 2011, p. 45). De acordo com Corrêa (2011, p. 46), as possibilidades de ação do Estado incluem, dentre outras:

a) estabelecer o marco jurídico (leis, regras, normas, posturas) de produção e uso do espaço;

b) taxar a propriedade fundiária, as edificações, o uso da terra e as atividades produtivas: diferenciais espaciais dessa taxação refletem e condicionam a diferenciação socioespacial no espaço urbano;

c) controlar o mercado fundiário, tornando-se, sob certas condições, proprietário de glebas que poderão ser permutadas com outros agentes sociais;

d) tornar-se promotor imobiliário, investindo na produção de imóveis residenciais em determinados locais do espaço intraurbano para determinados grupos sociais.

Para o autor, essa ação tende, usualmente, a reforçar a diferenciação intraurbana no que diz respeito à segregação residencial (CORRÊA, 2011, p. 46). Outro aspecto importante é possibilitar que a terra não seja objeto de especulação e cumpra sua função social exigida pela Constituição Federal aprovada em 1988 (BRASIL, 1988) e pelo Estatuto da Cidade (BRASIL, 2001).

Siqueira (2007, p. 4) ressalta que segregação socioespacial tende a aumentar com a ilegalidade urbana. Mas o que é ilegal no aspecto fundiário? De acordo com Cardoso (2003, p. 37), existem diversos tipos de irregularidades urbanas, entre essas:

- Irregularidade da situação de propriedade da terra ou do imóvel como resultado de processos de ocupação da terra ou de edificações;

- Irregularidade parcial ou a inadequação da documentação de propriedade existente que não configurem processos de ocupação, mas que apresentem problemas de registro ou assemelhados; - Irregularidade de processos de produção de loteamentos, diferenciando-se os clandestinos (lotes que não contam com processo de licenciamento na prefeitura) e os irregulares (lotes que apresentam problemas na tramitação do processo de licenciamento, sem conclusão efetiva).

Considerando essa situação, Maricato (2003, p. 157) afirma que

a maior tolerância e condescendência em relação à produção ilegal do espaço urbano vem dos governos municipais aos quais cabe a maior parte da competência constitucional de controlar a ocupação do solo. A lógica concentradora da gestão pública urbana não admite a incorporação ao orçamento público da imensa massa, moradora da cidade ilegal, demandatária de serviços públicos. Seu desconhecimento se impõe, com exceção de ações pontuais definidas em barganhas políticas ou períodos pré-eleitorais.

Entretanto, mesmo com essas anomalias, há normativas claras sobre o processo de regularização fundiária. Conforme Tierno e Carvalho (2007), nos procedimentos de regularização fundiária, para loteamentos irregulares ou clandestinos, e em áreas públicas ocupadas informalmente, é usual encontrarmos bases imobiliárias com descrições dúbias, omissas ou incompletas.

Esse fato é facilmente constatado quando se realiza o levantamento cadastral do assentamento 
informal. Ao pretender confrontar o imóvel descrito no registro de imóveis com aquele efetivamente existente e parcelado, percebemos que não há correspondências entre eles: inexistem ou faltam as medidas perimetrais, falta ou sobra área, os marcos não existem mais, etc. (TIERNO; CARVALHO, 2007, p. 248).

A Secretaria de Assuntos Estratégicos (2011, p. 7) define regularização fundiária como "a ação de reconhecimento do direito à moradia da população, garantindo-se a segurança da posse nas áreas ocupadas, em que não existe o registro dos imóveis. $\mathrm{Ou}$ seja, é legitimar a posse de quem ocupa o imóvel". Em uma publicação sobre regularização fundiária urbana, o Governo Federal reafirma que a regularização fundiária permite que os moradores que residem em terrenos sem o documento definitivo se tornem "seus legítimos ocupantes ou proprietários, garantindo dessa forma a segurança da moradia" (SECRETARIA DE ASSUNTOS ESTRATÉGICOS, 2011, p. 7). Portanto, a Lei n. 11.952, editada pelo Governo Federal em 2009, dispõe sobre a regularização fundiária das ocupações incidentes em terras situadas em áreas da União, no âmbito da Amazônia Legal. Para Gouvêa, Ávila e Ribeiro (2009, p. 88), a edição dessa Lei pode simplificar "os procedimentos e exigências para a doação ou concessão de terras do Incra e da União aos municípios, de modo a realizar a regularização fundiária de suas áreas urbanas".

Entretanto, essa Lei tem seu foco no espaço urbano dos municípios que foram alvo de políticas de ocupação da Amazônia ao longo da década de 1970. E como ficariam as cidades que ocupam a área da várzea do rio Amazonas, onde se encontram as cidades mais antigas da Região, mas que também possuem um quadro de irregularidade fundiária urbana? Nessa área da várzea, de acordo com Costa e Brondizio (2011), 42,5\% das cidades foram fundadas antes de 1910 e, em torno de $66 \%$, antes de 1950 . Segundo esses autores, $70 \%$ das cidades, localizadas na várzea, concentram $8,2 \%$ da população dessa área; são cidades que, apesar de pequenas, continuam a atrair população, pois oferecem a seus moradores, no mínimo, possibilidades de mudar suas vidas e acessar novas oportunidades econômicas.

Nesse sentido, é importante que pesquisas sejam desenvolvidas visando compreender a situação fundiária urbana da região, até mesmo das pequenas cidades, e possibilitar a definição de instrumentos efetivos de legalização da terra urbana. Segundo Gouvêa, Ávila e Ribeiro (2009, p. 86),

embora as médias apresentadas pelos municípios da Amazônia legal em termos de disponibilidade de instrumentos de política e planejamento urbano sejam superiores ou semelhantes às apresentadas pelo país, muito ainda necessita ser feito não só na construção desse arsenal nos municípios que ainda não dispõem dos instrumentos necessários à gestão do crescimento de suas áreas urbanas, mas também na capacitação de todos os municípios na efetiva implementação de suas políticas de desenvolvimento.

\section{A situação fundiária urbana em uma pequena cidade da amazônia: o caso de ponta de pedra}

Ponta de Pedras localiza-se na ilha de Marajó, no estado do Pará (Figura 1). De acordo com o IBGE (2012), esse município possuía quase 30 mil habitantes em 2010, distribuídos entre a área urbana (48\%) e o interior do município (52\%). A base da economia do município é a produção do açaí; o munícipio ocupa o segundo lugar no ranking nacional, responsável por 10\% dessa produção (IBGE, 2012).

Essa economia tem se dinamizado desde o início dos anos 1990, em função de sua incorporação pelo mercado global. De acordo Costa, Montoia e Lima (2012), a produção de açaí dinamizou a economia urbana e apresenta seus desdobramentos no crescimento urbano.

Apesar da importância econômica, a produção do açaí não gera recursos, de forma direta, para o Município, pois é considerada 'atividade extrativista em área de proteção ambiental', impossibilitando taxar a produção. No entanto, o comércio do açaí abriu muitas possibilidades de aumento da renda familiar, fazendo com que o pequeno produtor (produção familiar), principalmente, consiga acumular recursos suficientes para viver na entressafra, que ocorre, na região, entre fevereiro e agosto (COSTA; MONTOIA; LIMA, 2012, p. 66).

Como resultado de uma crescente demanda de mercado, durante os últimos 20 anos, a população ribeirinha do município teve acesso às técnicas 

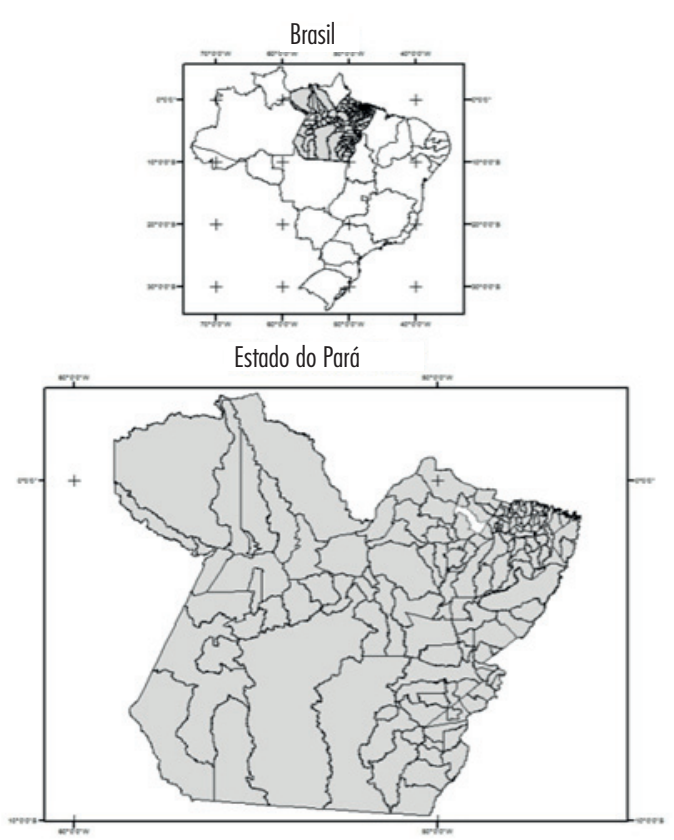

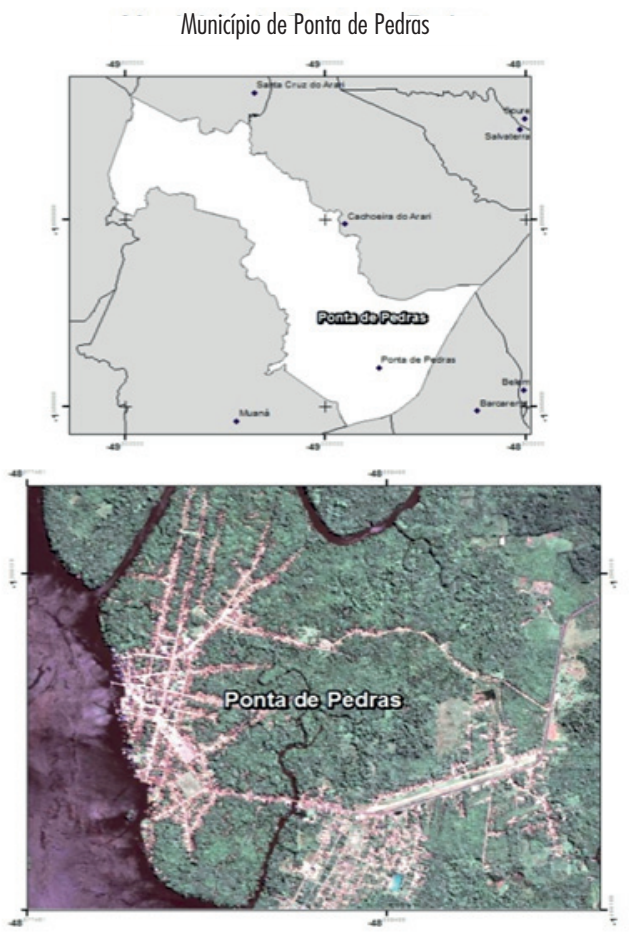

Figura 1 - Localização da cidade de Ponta de Pedras

Fonte: Elaborado pelos autores a partir de IBGE, 2012; GOOGLE EARTH, 2010

agroflorestais desenvolvidas, e isso fez com que a produção do açaí crescesse, o município se tornasse o segundo produtor nacional desse produto, sendo essa atividade a principal fonte de renda para a população (BRONDIZIO, 2008).

Em estudos sobre o crescimento urbano de Ponta de Pedras, Costa, Montoia e Lima (2012) quantificaram, entre 1991 e 2010, um crescimento da área urbana de $126 \%$ e da população urbana maior que $111 \%$, situação que, segundo os autores, está associada à intensificação da importância do açaí no mercado mundial e de sua produção no município. Em relação ao local de origem da população, esses autores observaram que $65 \%$ dos chefes de domicílios entrevistados em pesquisa realizada em julho de 2010 nasceram na cidade de Ponta de Pedras e, consequentemente, sempre viveram na área urbana do município, e $12 \%$ das famílias viviam na cidade havia menos de dez anos.

De acordo com o Censo de 1991 (IBGE, 2012), existiam 1.084 domicílios urbanos na cidade de Ponta de Pedras; entre 1991 e 2000, houve um incremento de $38 \%$ ao total de domicílios urbanos existentes. Em 2000, o número de domicílios urbanos correspondia a $47 \%$ do total, e entre 2000 e 2010, esse percentual aumentou para 52\%. Em dez anos, houve um incremento de $41 \%$ ao número de domicílios urbanos. Apesar dos questionamentos que podemos levantar sobre o rigor da contagem de domicílios utilizada para o Censo, esses dados nos permitem observar que a cidade aumentou e o número de residências urbanas também teve um crescimento significativo.

Diante desse cenário, algumas questões emergem e movem nossa pesquisa, tais como: qual a situação desses imóveis em relação à regularização fundiária? Qual o processo de transferência de propriedade predominante? Há algum indicador de que o poder público local está seguindo as diretrizes da União em relação à política de regularização fundiária? Essas e outras discussões são importantes para a compreensão do que é a cidade legal nessa realidade urbana tão peculiar, e similar a outras realidades urbanas na Amazônia. 
Ponta de Pedras no contexto da regularização fundiária urbana

De acordo com o Estatuto da Cidade (BRASIL, 2001), capítulo III, art. 40, o Plano Diretor é um instrumento importante e básico da política de desenvolvimento e expansão urbana, e é parte "integrante do planejamento municipal". É nesse instrumento que deve ser inserida a política municipal de regularização fundiária. Atendendo às prerrogativas dessa Lei, o Plano Diretor do Município de Ponta de Pedras foi elaborado e aprovado em 2006. Entretanto, para Montoia (2010, p. 105), ele apresenta várias inconsistências, é generalista, além da nítida impressão de atendimento formal a uma obrigatoriedade, que era a sua elaboração.

Em relação à política fundiária urbana, o Plano, em seu art. 9, item VIII, afirma que

haverá a 'regularização fundiária e urbanização das áreas ocupadas por população de baixa renda mediante o estabelecimento de normas especiais de urbanização, uso e ocupação do solo e edificação, consideradas a situação socioeconômica da população e as normas ambientais'. Como será essa regularização? Onde estão estas populações de baixa renda? [...] O Plano Diretor do município de Ponta de Pedras reflete uma dimensão sócio-espacial imaginária. Esconde, em seus artigos, o que é a cidade, e não determina claramente o que será feito, porque ações tão gerais 'podem ser tudo ou nada' (MONTOIA, 2010, p. 110).

Dessa forma, o Plano Diretor de Ponta de Pedras não apresenta como é a realidade urbana do município e como seria conduzida, de fato, uma política de regularização fundiária. Esse descompasso de informação também aparece nos dados levantados em campo.

Para entender como os moradores da cidade percebem essa situação, foi aplicado, em julho de 2010, um formulário a 352 domicílios urbanos ${ }^{1}$, o que correspondia a mais de $11 \%$ do total de domicílios urbanos existentes em 2010 (IBGE, 2012), com um intervalo de confiança de 95\% simples.

Para chegarmos ao número de domicílios que seriam alvo da aplicação dos questionários, obtivemos, do IBGE, as informações sobre os limites/divisão dos setores censitários e o número de domićlios por setor. Assim, foi possível estimar o número de questionários que seriam aplicados em cada setor censitário, seguindo, assim, uma amostragem estratificada simples, pois o número de questionários por setor seguiu a proporção do número de domicílios existentes nesses setores, os quais não eram homogêneos; o cálculo do número de questionários por setor seguiu o mesmo padrão, $10 \%$ dos domicílios do setor.

No processo de aplicação desses questionários, optou-se por uma distribuição aleatória, ou seja, os questionários foram aplicados nas faces das ruas, selecionando-se um domicílio e saltando dois, na mesma face, cobrindo-se todas as ruas do setor, de modo a selecionar os domicílios alvos de forma aleatória. Esse processo de aplicação dos questionários levou dez dias e seguiu o ritmo da população. Em função da temperatura e da umidade elevadas, o grupo de pesquisadores - composto por seis pessoas envolvidas com o projeto, entre alunos da graduação, do mestrado e outros pesquisadores - entrevistava o chefe do domicílio, no período das $8 \mathrm{~h}$ às $11 \mathrm{~h} 30$, quando todo o comércio fecha para a "sesta", e retornava ao trabalho às $16 \mathrm{~h}$, com o clima mais ameno, trabalhando até as $19 \mathrm{~h}$.

O questionário foi composto por 40 questões, contendo informações sobre o perfil do morador urbano: local de nascimento, tempo de residência, rendimentos, redes sociais que estabelece etc. Uma das questões perguntava ao entrevistado se a família era proprietária do imóvel - 88\% responderam positivamente. Ressalta-se que a porcentagem de respostas afirmativas variou, em relação aos setores censitários, de $75,8 \%$ a $96,7 \%$, sendo que o maior percentual foi verificado no setor 22, considerado, pelo Poder Público local, como área invadida.

Aos entrevistados que responderam positivamente à questão mencionada, havia uma segunda questão, investigando se possuíam título de propriedade. No Gráfico 1, é possível observar as respostas mais comuns. Considerando o total de respostas afirmativas, $5,2 \%$ responderam que não possuíam contrato, $20,3 \%$ não responderam a essa questão, 36,5\% afirmaram possuir escritura e $38 \%$ disseram que possuíam apenas um contrato de compra e venda.

1 Pesquisa certificada no Comitê de Ética em Pesquisa - CEP da UNIVAP sob o número H137/CEP/2010 


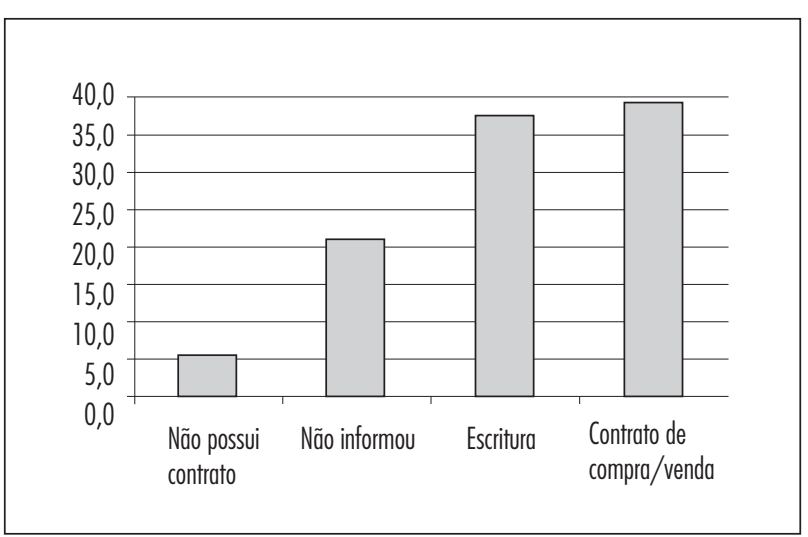

Gráfico 1 - Porcentagem de entrevistados que possuem título de propriedade Fonte: Dados da pesquisa.

Dessa forma, observamos que a propriedade da terra, para os moradores, está associada à aquisição do imóvel e não à garantia da propriedade, legitimada por meio da formalização do registro em cartório.

Outra questão investigada dizia respeito à forma de aquisição do imóvel, apresentada no Gráfico 2. Percebemos que a aquisição por compra é o sistema mais comum $(43,5 \%)$ e a transferência da propriedade, ou parcela da propriedade, por herança também é muito usual (35\%). Nesse caso, verificamos que um lote, ou gleba, inicialmente ocupado

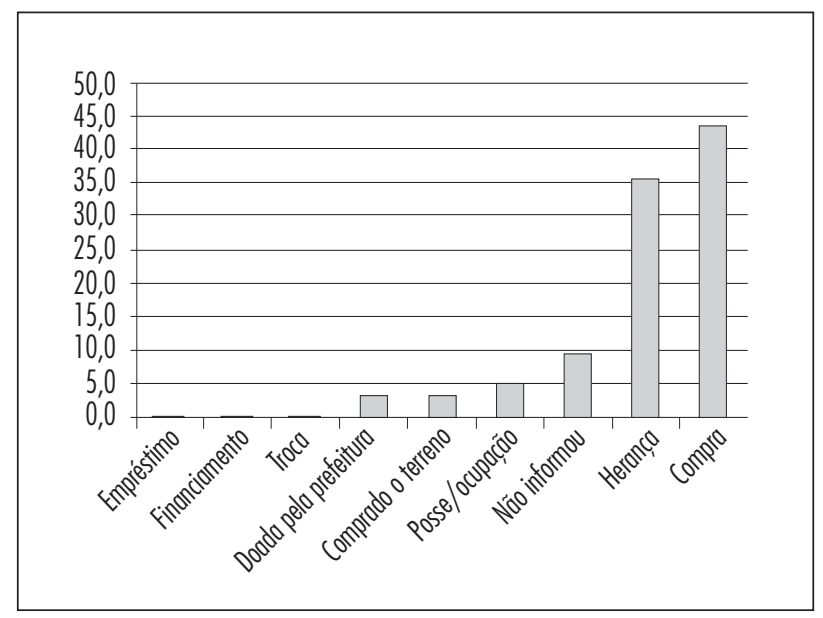

Gráfico 2 - Forma de aquisição do imóvel pelo entrevistado Fonte: Dados da pesquisa. por uma família ou indivíduo, pode ser divido, de acordo com o número de herdeiros, por meio do parcelamento da área previamente ocupada. É comum encontrarmos membros de uma mesma família (pais, filhos, tios, sobrinhos) residindo em uma mesma rua, formando "vilas de parentes", situação usual nas comunidades ribeirinhas.

Esses dados tornam-se mais interessantes quando analisados em conjunto com outras informações levantadas em campo, tais como quantidade de registros de imóveis no cartório local e cadastro dos imóveis que pagam IPTU.

Em trabalho de campo, realizado em julho de 2011 na cidade de Ponta de Pedras, foram coletados dados do acervo documental sobre o registro de imóveis, disponível no cartório do município, utilizando o método de cópia por imagens fotográficas. 0 acesso a essa informação foi possível após a autorização do tabelião responsável. 0 trabalho de coleta dos dados foi realizado ao longo de dois dias, pela equipe da pesquisa. Essas informações foram tabuladas durante oito meses de trabalho, pois houve dificuldade na leitura: tanto por serem manuscritos quanto pelo fato de a qualidade de algumas fotografias dos documentos de registro de imóveis (5\%) estar comprometida. Foram analisadas 406 matrículas de imóveis urbanos referentes aos livros 2, 2A, 2B, 2C e 2D. As matrículas contêm um total de 1.204 registros, referentes ao período de 1899 a 2011.

Em outro levantamento de campo, realizado em julho de 2012, foi possível ter acesso ao novo cadastro de imóveis urbanos da Prefeitura Municipal, o qual possibilita a cobrança do IPTU (Imposto Predial e Territorial Urbano). Importante destacar que a cobrança do IPTU não era prática no município, em função do prejuízo político que essa cobrança poderia causar ${ }^{2}$. Para se ter uma ideia, em 2007, o pagamento desse imposto representava $0,04 \%$ da arrecadação anual municipal. Esse valor aumentou para, aproximadamente, 10\% em 2012, em função da reestruturação do setor financeiro e de arrecadação de tributos da Prefeitura.

Considerando-se as informações levantadas sobre o número de imóveis registrados no cartório e do cadastro do IPTU, foi elaborada a Tabela 1. De 1899

\footnotetext{
2 Segundo entrevista com o Secretário de Finanças do município, em 2009, essa prática era adotada, historicamente, por diferentes prefeitos.
} 
a 2011, foram registrados no cartório local 722 imóveis urbanos, enquanto a Prefeitura tem 1.888 imóveis urbanos cadastrados, para efeito de cobrança do IPTU. Há uma dissonância de 1.166 imóveis urbanos, ou seja, a Prefeitura "reconhece" a existência de $161,5 \%$ a mais de imóveis do que aqueles que estão registrados no cartório local.

Tabela 1 - Número de Imóveis Urbanos na Cidade de Ponta de Pedras, PA

\begin{tabular}{lc}
\hline Número de imóveis considerados regularizados na área urbana \\
\hline Fonte da Informação & N. \\
\hline Prefeitura - Imóveis cadastrados para cobrança do IPTU (2012) & 1.888 \\
Imóveis registrados no cartório (1899 a 2011) & 722 \\
N. domićlios urbanos - IBGE (2010) & 3.096 \\
\hline
\end{tabular}

Fonte: Dados da pesquisa

Ao cobrar o IPTU, de certo modo, a Poder Público local referenda a existência desses imóveis como legais e, pressupõe-se, essa cobrança pode se reverter em investimentos públicos em infraestrutura e serviços. Em trabalho de campo realizado em julho de 2012, foi possível observar que, desde implantado o sistema de cobrança do IPTU, houve investimentos, que podem ser considerados, a despeito de discussões ambientais, melhorias para a população. A Figura 2 apresenta duas fotografias obtidas do mesmo local, mostrando o aterro de uma área alagada, periodicamente, pela vazão do rio Marajó-Açú, no bairro Jagarajó. Esse aterro, de acordo com os moradores, propiciou o acesso de ambulância e caminhões de lixo no local, o que não acontecia antes pela impossibilidade de deslocamento de veículos.

Para fornecermos uma ideia da quantidade de imóveis que estão fora do mercado formal, comparamos dados oficiais, obtidos no cartório da cidade e na Prefeitura de Ponta de Pedras, com os dados sobre domicílios existentes no perímetro urbano de Ponta de Pedras, em 2010, de acordo com o Censo realizado pelo IBGE (2012). Considerando sua definição, domicílio não é sinônimo de imóvel ${ }^{3}$. Informações coletadas na Prefeitura sobre o IPTU referem-se ao imóvel dos moradores urbanos, assim como o registro no cartório é do imóvel, e não apenas do domicílio. 0 Censo considera apenas o domicílio como unidade básica de seus
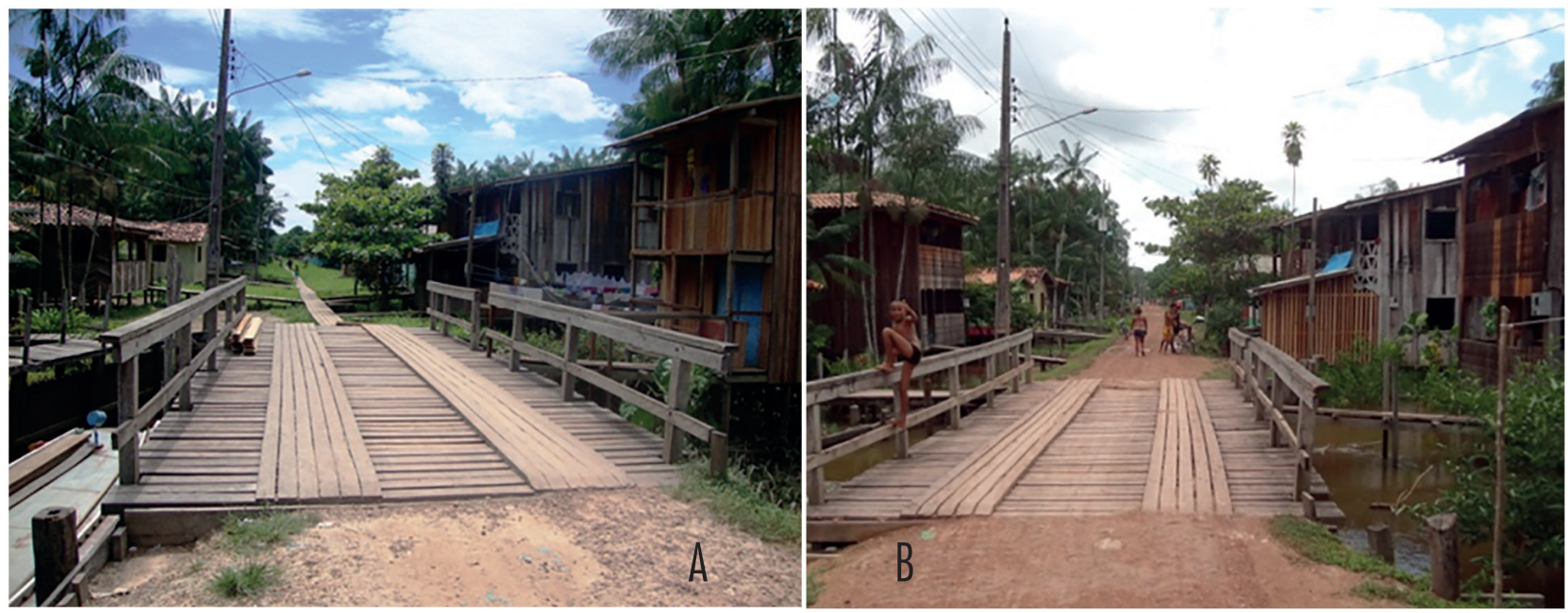

Figura 2 - Fotografias da Rua Antero Lobato, que possuía acesso, com aterro, até a ponte em evidência na imagem (a), obtida em 2010. Após a ponte, havia uma travessa no sistema de "ponte", como são conhecidas as ruelas em madeira, usuais na cidade e que permitem o acesso às palafitas. Em 2012, fotografia (b), aterraram 0 acesso.

Fotos: COSTA, S. M. F. et al., 2010, 2012.

3 Neste artigo, assumimos a definição de imóvel como "terreno ou prédio localizado em região urbana e que não se destina à exploração extrativista agrícola, pecuária ou agroindustrial” (JUSBRASIL, 2012). Já domicílio seria o lugar onde um indivíduo, “de modo definitivo, estabelece a sua residência e o centro principal da sua atividade" (BEVILÁQUA apud LEITE, 2006). 
levantamentos. Entretanto, essa comparação pode nos fornecer indicadores da dimensão da inconsistência entre informações que podem subsidiar discussões sobre legalidade urbana.

Existiam, em 2010, de acordo com o IBGE (2012), 3.096 domicílios urbanos. Desse total, 722 imóveis urbanos haviam sido registrados no cartório, e 1.888 cadastrados pela Prefeitura. Esses valores correspondem a, aproximadamente, $23 \%$ e $60,9 \%$ do total de domicílios levantados pelo IBGE (2012), respectivamente. Se considerarmos as informações do "survey" de 2010, 36,5\% dos domicílios entrevistados afirmaram possuir escritura. Nesse sentido, há informações divergentes sobre qual seria a extensão da cidade regularizada, portanto legal, em três instâncias diferentes: o Poder Público, o poder civil extrajudiciário e os moradores urbanos.

Como mencionado, de acordo com alguns autores, a cidade legal é contemplada pelo poder público com investimentos em infraestrutura e é valorizada pelo mercado imobiliário. A "cidade ilegal" se refere à porção não reconhecida pelo poder público em termos de planos urbanísticos, apontada por Maricato (2002, p. 152), como o "lugar fora das ideias". Nas pequenas cidades da Amazônia, como Ponta de Pedras, não se pode falar em valorização pelo mercado imobiliário. Entretanto, quando o Poder Público coloca em prática um imposto que não era cobrado em função de uma política que pode ser considerada assistencialista, e esses recursos se revertem em benefícios para o conjunto da população (Figura 3), explicita-se, de forma enviesada, o que é a cidade regularizada. Nessa realidade urbana tão particular, seria mais adequada a expressão as "ideias fora do lugar", pois discussões são concebidas e políticas são propostas sem que se examine, criticamente, a pertinência da realidade socioespacial dessas propostas.

Nesse aspecto, a Lei n. 11.952/2009, que menciona a situação das terras devolutas estaduais na Amazônia Legal - que foram federalizadas para a implantação de projetos de colonização ou concessão de terras e exploração de indústrias de interesse nacional -, não incorpora às suas deliberações as cidades antigas da Amazônia Legal e que, igualmente à região da Fronteira Agrícola, também possui problemas de regularização fundiária urbana. Muitas dessas cidades avançaram sobre áreas de várzea e os procedimentos de registro de imóveis são, da mesma

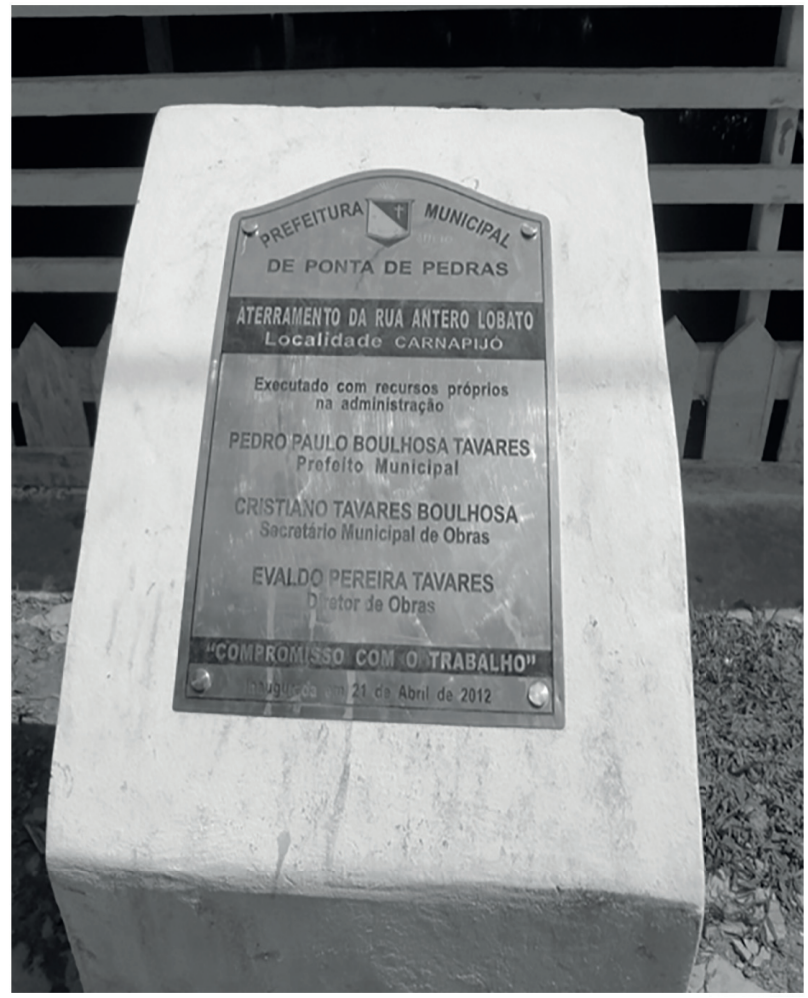

Figura 3 - Fotografia de uma obra pública, de pavimentação de uma rua da cidade de Ponta de Pedras, ressaltando-se que o recurso para tal investimento é "próprio", em uma alusão ao aumento da arrecadação municipal Foto: COSTA, S. M. F. et al., 2012.

forma, muito confusos, como ocorre na cidade de Ponta de Pedras.

Além de poucos imóveis serem registrados no cartório na cidade de Ponta de Pedras, há várias inconsistências nos documentos analisados. Observou-se, durante a leitura dos registros, que vários imóveis que foram parcelados ou unificados possuem matrícula de mesmo número, o que contraria as normas brasileiras sobre registro de imóveis, que estabelecem que cada parcela de terreno receba um número de matrícula exclusivo. Ocorre, também, que, em alguns casos, não há continuidade nos registros de transferência de propriedade, isto é, algumas transferências intermediárias não constam no documento. Mesmo com essas distorções, há informações importantes nesses documentos, como o número de imóveis registrados no cartório da cidade, por década (Gráfico 3).

Nos documentos investigados, constatou-se que a Prefeitura aparece como primeiro proprietário em 86,45\% das matrículas. Em algumas 


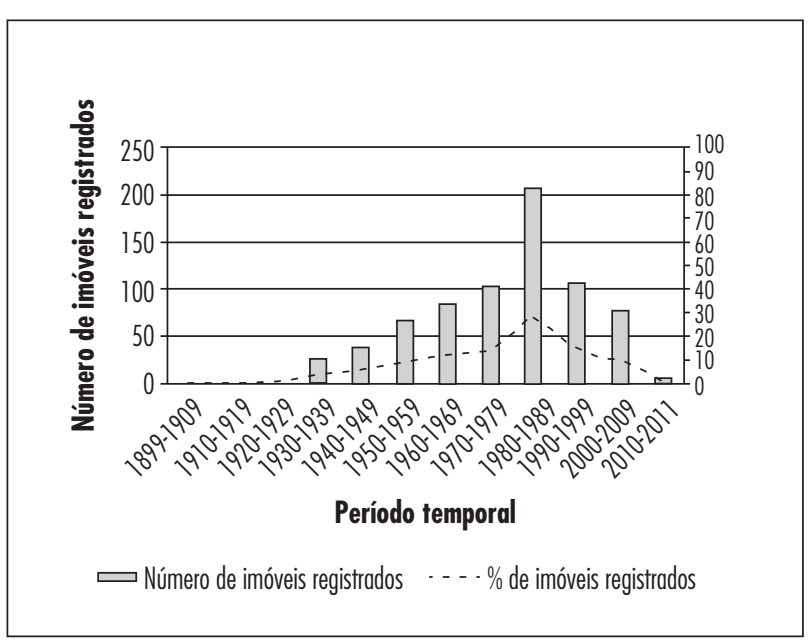

Gráfico 3 - Gráfico da distribuição do número de imóveis registrados no cartório da cidade, por década

Fonte: Dados da pesquisa.

décadas, houve um maior número de registros, como podemos observar no Gráfico 3. Há um pico de registro de imóveis entre 1980 e 1989, sendo que $30,1 \%$ dos imóveis foram registrados nesse período. Nessa mesma década, 59,35\% dos imóveis registrados pertenciam à Prefeitura.

Não é objetivo deste artigo discutir as formas de transferência de propriedade na cidade de Ponta de Pedras, porém desperta curiosidade perceber que o aforamento aparece, nos registros, como prática muito usual de transferência de imóvel. Das transferências realizadas tendo a Prefeitura como proprietário original do imóvel, o aforamento ocorre com maior destaque, representando 93,4\% das ocorrências. Ressalta-se que o aforamento é a transferência "do domínio útil e perpétuo de um imóvel por seu proprietário, sob o pagamento de um foro anual" (JUSBRASIL, 2012, sem página), que se realizava ainda no período do Império e constava no Código Civil de 1916. De acordo com levantamentos realizados durante trabalho de campo em julho de 2012, não se constatou o pagamento, por parte do proprietário desses imóveis, de nenhuma taxa de uso à Prefeitura. Quando analisamos para quem esses imóveis foram aforados, observamos que 39,41\% dos aforamentos foram feitos para famílias consideradas tradicionais ${ }^{4}$ de Ponta de Pedras.

Essas informações, apesar de preliminares, permitem-nos perceber que ainda há muito a ser pesquisado sobre o parcelamento fundiário urbano em Ponta de Pedras, que representa apenas uma das questões a serem debatidas e resolvidas na cidade. A situação fundiária urbana, observada na documentação cartorial dos imóveis de Ponta de Pedras, é apenas o reflexo do contexto regional e nacional em que essa e muitas outras pequenas cidades se inserem - nesse caso, a Região Amazônica.

\section{Considerações finais}

O processo de ocupação/urbanização do território carrega uma herança histórica, relacionada ao período da colonização do Brasil. Naquela época, aqueles que não eram de confiança da Coroa eram excluídos no que se refere ao acesso a terra. Com a aprovação da Lei de Terras, o Estado institucionalizou a exclusão ao acesso a terra daqueles que não tinham poder econômico. A situação não mudou muito no decorrer do tempo e, desde então, pouco tem sido feito para que se viabilize o acesso legal a terra.

Apesar da iniciativa do IPTU, a não regularização fundiária predomina na cidade de Ponta de Pedras. O Plano Diretor do município ainda reflete a realidade política e socioeconômica do lugar, com práticas políticas que não consideram o cidadão. Essa "nebulosa" em que se transformou o Plano Diretor não é prerrogativa exclusiva desse município. Essa situação se reproduz em vários outros locais, em função da ausência de uma discussão sobre reforma urbana. Apontar o Plano Diretor como um instrumento da política urbana que não conduz a uma reforma urbana não vai mudar realidades.

A informalidade urbana é comum à maioria das cidades brasileiras. De uma forma geral, essa irregularidade é o resultado do processo de ocupação do território da cidade, que exclui a população de baixo poder aquisitivo do mercado formal da habitação e, consequentemente, impede-a de exercer sua cidadania plenamente.

\footnotetext{
4 Famílias tradicionais são aquelas que possuem tradição política e soberania econômica no município, desde o século XIX. Sobrenomes usuais no comando político do município pertencem às famílias Tavares, Boulhosa, Lobato, Castro, dentre outras.
} 
Essa situação causa ao cidadão uma insegurança permanente. Portanto, cabe ao Estado pensar políticas que garantam esse direito social. A Lei n. 11.977/2009 é um grande passo em direção à construção de uma agenda efetiva sobre a regularização fundiária urbana no Brasil. Entretanto, a Lei de regularização fundiária urbana, proposta pelo Governo Federal e que se direciona mais especificamente para a Amazônia da fronteira agrícola, não privilegia uma realidade urbana significativa. 0 Estado não pode deixar de pensar o problema fundiário urbano das pequenas cidades da várzea do Rio Solimões - Amazonas, secular em termos de ocupação e com problemas estruturais em termos de regularização fundiária. A realidade desse urbano é muito peculiar e não pode ser ignorado pelos tomadores de decisão.

0 que é a cidade legal em um contexto em que o Poder Público local, ao assumir uma conduta de cobrança de IPTU, inclui mais de 200\% dos imóveis registrados em cartório? Assim como em Ponta de Pedras, essa situação também pode ser encontrada em outras cidades amazônicas, e esse pode ser um fio condutor para a regularização fundiária. Ao pagar imposto, o morador urbano se sente parte da cidade, cidadão de fato. Assim, o Estado não pode ignorar a cidade real, que inclui o morar irregularmente, o estar em situação permanente de insegurança. Moradia regularizada é um direito social e uma das condições para se ter qualidade de vida.

Uma discussão que precisa avançar, em relação à regularização fundiária nas cidades da Região Amazônia, refere-se a essa noção de urbano e à percepção da população e do poder público locais sobre as formas de apropriação desse espaço, discussão importante para subsidiar a elaboração de políticas regionais que viabilizem o desenvolvimento regional com qualidade de vida.

O Governo Federal propôs leis e instrumentos urbanos para viabilizar a regularização fundiária urbana: Lei Federal n. 10.257 (Estatuto da Cidade), Lei Federal n. 10.931 (gratuidade do primeiro registro), Lei Federal n. 11.481 (regularização fundiária em terras da União), Lei Federal n. 11.977/2009 (Dispõe sobre o Programa Minha Casa, Minha Vida - PMCMV e a regularização fundiária de assentamentos localizados em áreas urbanas), Lei Federal n. 11.952 (regularização fundiária na Amazônia). Entretanto, esses instrumentos e as leis foram pensados para a realidade urbana das grandes cidades, e não para cidades pequenas, como Ponta de Pedras, com universo tão particular. Esse é um tema que precisa ser enfrentado pelo Ministério das Cidades, a despeito das elites locais, considerando que mais de $80 \%$ das cidades brasileiras podem ser caracterizadas como pequenas cidades (menos de 20 mil habitantes).

\section{Agradecimentos}

Os autores agradecem à Fapesp (Fundação de Amparo à Pesquisa do Estado de São Paulo) e ao CNPq (Conselho Nacional de Desenvolvimento Científico e Tecnológico) pelo apoio financeiro fornecido à condução dessa pesquisa, sem o qual seu desenvolvimento seria inviável.

\section{Referências}

ANDRADE, M. C. O. A questão da terra na primeira república. In: SILVA, S.; SZMRECSANYI, T. (Org.). História econômica da primeira república. São Paulo: HucitecAbphe, 1996. p. 143-152.

BRASIL. Constituição (1988). Constituição: República Federativa do Brasil. Brasília, DF: Senado Federal, 1988. Disponível em: <http://www.planalto.gov.br/ccivil_03/ constituicao/constituiçao.htm>. Acesso em: 8 abr. 2011.

BRASIL. Lei n. 10.257, de 10 de julho de 2001. Regulamenta os arts. 182 e 183 da Constituição Federal, estabelece diretrizes gerais da política urbana e dá outras providências. Diário Oficial [da] República Federativa do Brasil, Brasília: DF, 11 jul. 2001. Disponível em: <http://www.planalto.gov.br/ccivil_03/leis/LEIS_2001/ L10257.htm>. Acesso em: 08 abr. 2011.

BRASIL. Lei n. 11.977, de 7 de julho de 2009. Diário Oficial [da] República Federativa do Brasil, Brasília: DF, 8 jul. 2009. Disponível em: <http://www.planalto.gov. br/ccivil_03/_ato2007-2010/2009/lei/l11977.htm>. Acesso em: 20 jan. 2012.

BRONDIZIO, E. S. The Amazonian caboclo and the açaí palm: forest farmers in the global market. New York: The New York Botanical Garden, 2008.

CORRÊA, R. L. 0 espaço urbano. Rio de Janeiro: Ática. 2011. 
COSTA, E. V. da. Da monarquia à república: momentos decisivos. São Paulo: Ed. Unesp, 1999.

COSTA, S. M. F.; BRONDIZIO, E. Cities along the floodplain of the Brazilian Amazon: characteristics and trends. In: PINEDO-VASQUEZ, M. et al. (Ed.). Amazon Varzea - The decade past and the decade ahead. New York: Springer, 2011.

COSTA, S. M. F. et al. As cidades pequenas do estuário do rio Amazonas: crescimento urbano e rede sociais da cidade de Ponta de Pedras, PA. In: SIMPÓSIO NACIONAL DE GEOGRAFIA URBANA - SIMPURB, 11., 2009. Anais... Brasília: AGB, 2009.

COSTA, S. M. F.; MONTOIA, G.; LIMA, V. M. Pequenas cidades do estuário do Rio Amazonas: fluxo econômico, crescimento urbano e as novas velhas urbanidades da pequena cidade de Ponta de Pedras. Revista Redes, v. 17, n. $2,2012$.

GOUVÊA, D. C.; ÁVILA, P. C.; RIBEIRO, S. B. A regularização fundiária urbana na Amazônia legal. Revista Brasileira de Estudos Urbanos e Regionais, v. 11, n. 2, 2009. Disponível em: <http://www.anpur.org.br/revista/rbeur/index.php/rbeur/article/.../221/205>. Acesso em: 27 jul. 2012.

INSTITUTO BRASILEIRO DE GEOGRAFIA E ESTATÍSTICA - IBGE. Banco de Dados Agregado. 2012. Disponível em: <http://www.sidra.ibge.gov.br>. Acesso em: 3 maio 2012.

JUSBRASIL. Definições para imóvel urbano. 2012. Disponível em: http://www.jusbrasil.com.br/topicos/297832/imovel-urbano. Acesso em: 01/07/2012.

LEITE, G. Domicílio: um complexo conceito do Direito Civil. 2006. Disponível em: http://www.boletimjuridico.com.br/doutrina/texto.asp?id=1632. Acesso em: 01/07/2012.

MARICATO, E. Habitação e cidade. São Paulo: Atual, 1997.

MARICATO, E. As idéias fora do lugar e o lugar fora das idéias. In: ARANTES, O.; VAINER, C.; MARICATO, E. A cidade do pensamento único: desmanchando consensos. Petrópolis: Vozes, 2002.

MARICATO, E. Metrópole, legislação e desigualdade. Estudos Avançados, v. 48, n. 17, p. 151-167, 2003.
MONTOIA, G. R. M. Planejamento participativo em pequenas cidades da Amazônia: um estudo de caso no município de Ponta de Pedras. 142p. 2010. Dissertação (Mestrado) - Universidade do Vale do Paraíba, São José dos Campos, 2010.

SECRETARIA DE ASSUNTOS ESTRATÉGICOS PRESIDÊNCIA DA REPÚBLICA. Guia para regularização fundiária urbana na Amazônia: escritura para todos. Brasília, 2011.

ROLNIK, R. A construção de uma política fundiária e planejamento urbano para o país- avanços e desafios. 2006. Disponível em: <http://desafios2.ipea.gov. br/agencia/images/stories/PDFs/politicas_sociais/ensaio1_raquel12.pdf>. Acesso em: 1ํo jul. 2012.

SIQUEIRA, J. P. F. H. A questão fundiária urbana. 2007. Disponível em: <http://www.ripj.com/art_jcos/art_jcos/ num19/RIPJ_19/EX/19-10.pdf>. Acesso em: 08 abr. 2011.

TIERNO, R; CARVALHO, P. A. O registro imobiliário: Conceitos e Bases Legais. In: MINISTÉRIO DAS CIDADES. Manual de regularização fundiária plena. Brasília: Governo Federal, 2007.

VASCONCELOS, P. A. A utilização dos agentes sociais nos estudos de geografia urbana: avanço ou recuo? In: CARLOS, A. F. A.; SOUZA, M. L. de; SPOSITO, M. E. B. (Org.). A produção do espaço urbano. São Paulo: Contexto, 2011.

Recebido: 13/03/2013

Received: 03/13/2013

Aprovado: 02/07/2013

Approved: 07/02/2013 